\title{
Vegetative Compatibility Groups in Colletotrichum coccodes Subpopulations from Australia and Genetic Links with Subpopulations from Europe/Israel and North America
}

\author{
B. Ben-Daniel, D. Bar-Zvi, D. Johnson, R. Harding, M. Hazanovsky, and L. Tsror (Lahkim)
}

\begin{abstract}
First, fifth, and sixth authors: Department of Plant Pathology, Agricultural Research Organization, Gilat Research Center, M. P. Negev 85280, Israel; first and second authors: Department of Life Sciences, Ben-Gurion University, Be'er-Sheva, Israel; third author: Department of Plant Pathology, Washington State University, Pullman 99164-6430; and fourth author: Department of Plant Pathology, South Australian Research and Development Institute, GPO Box 397, Adelaide, SA 5001, Australia.
\end{abstract} Accepted for publication 15 November 2009.

\section{ABSTRACT}

Ben-Daniel, B., Bar-Zvi, D., Johnson, D., Harding, R., Hazanovsky, M., and Tsror (Lahkim), L. 2010. Vegetative compatibility groups in Colletotrichum coccodes subpopulations from Australia and genetic links with subpopulations from Europe/Israel and North America. Phytopathology 100:271-278.

Vegetative compatibility of 94 isolates of Colletotrichum coccodes from Australia originating from potato, soil, and a weed (Solanum esuriale) was tested using nitrate-nonutilizing (nit) mutants. Isolates distributed to six vegetative compatibility groups (VCGs), five of them multimember $(24.5,23.4,13.8,12.8$, and $7.5 \%$ distribution) and only one composed of two isolates $(2.1 \%) ; 15.9 \%$ of them were not assigned to any of the VCGs. Aggressiveness of 51 isolates representing all six VCGs was tested by mature green tomato bioassay: isolates assigned to AUS-VCG-4 were the most aggressive and those in AUS-
VCG-3 the least $(P<0.05)$. Isolates from warmer climates and lower latitudes were more aggressive $(P<0.05)$. In addition, we report for the first time complementations between isolates from Australia (AUS); North America (NA); and Israel, The Netherlands, Scotland, France, Germany (EU/I). Isolates assigned to AUS-VCG-4 anastomosed with isolates assigned to EU/I-VCG-7 and NA-VCG-5 (which also anastomosed with each other). Isolates assigned to EU/I-VCG-6 anastomosed with isolates assigned to NA-VCG-2 and isolates assigned to AUS-VCG-2 anastomosed with isolates assigned to EU/I-VCG-2. The linkage between subpopulations could result from the limited exchange of seed tubers among continents, or could be due to, for instance, gene flow, selection, or a limited number of polymorphic vegetative incompatibility genes.

Additional keywords: aggressiveness, anastomosis, black dot.
Potato black dot, caused by Colletotrichum coccodes (Wallr.) S. Hughes, is broadly distributed in all potato-growing regions of the world, but is most important in areas with dry, hot periods, such as the Mediterranean region, the western United States, South Africa, and southern Australia (17). In Australia, the rapid development of black dot within new production regions has led to it being recognized as a major disease. Although it affects both the fresh and processing industries by causing premature plant death and reduced yields by 12 to $30 \%$, the main effect is on the quality of washed potato (9). Potato black dot is characterized by small black sclerotia developing on senescent or dead plant tissue, roots, stems, stolons, and daughter tubers, thus reducing tuber quality and yield (7). Symptoms include brown lesions with black sclerotia on tubers, roots, and stem bases; premature senescence and wilting of aboveground plant parts $(17,28)$; and deep-sunken lesions on tubers stored at $>10^{\circ} \mathrm{C}(8)$. C. coccodes appears as a highly diverse species morphologically, physiologically, and genetically; the existence of vegetative compatibility groups (VCGs) might explain this diversity, despite the fact that no sexual stage is known for the pathogen $(7,28)$. Vegetative compatibility refers to the ability of isolates of the same fungal species to undergo mutual hyphal anastomosis and form viable heterokaryons. Strains that are vegetatively compatible with one another are

Corresponding author: L. Tsror (Lahkim); E-mail address: tsror@ volcani.agri.gov.il

doi:10.1094/PHYTO-100-3-0271

(c) 2010 The American Phytopathological Society described as members of the same VCG $(11,16,18,21,24)$. Vegetatively compatible isolates may form subpopulations that tend to be similar due to a common genetic pool, and may have similar phytopathological and physiological traits that differ from those of isolates that are not assigned to the same VCG (18). Classification of VCGs has been used to study the genetic structure of populations of plant-pathogenic fungi, including Fusarium oxysporum $(12,14,19,23)$, Verticillium spp. $(5,11,24)$, and Colletotrichum spp. $(3,13,21,22,25)$. Due to black dot's increasing economic impact in potato, a study of the structure of its populations worldwide has become a pressing issue. Exploring the diversity within a species may contribute to a better understanding of the disease epidemiology and help in improving its control. Nitzan et al. (21) demonstrated the occurrence of four multimember VCGs among $110 \mathrm{C}$. coccodes potato isolates that originated from Israel, France, and the Netherlands (referred to as Europe/Israel or EU/I isolates). Aggressiveness trials indicated that isolates of EU/I-VCG-3 were the most aggressive to potato (21). Shcolnick et al. (25) classified an additional $174 \mathrm{C}$. coccodes EU/I isolates, 73 of them assigned to the four previously reported groups and 76 assigned to four newly defined VCGs (a total of eight EU/I VCGs). Isolates from EU/I VCGs 5 and 6 were the most aggressive on potato, while isolates from EU/I-VCG-1 were the least aggressive (25). Nitzan et al. (22) demonstrated the occurrence of seven VCGs among 120 isolates collected from North America (referred to as NA VCGs), with isolates from NAVCG-2 and -5 being the most aggressive on potato (22). However, recently, Aqeel et al. (1) reported that NA-VCG-2 and -6 are the 
most aggressive. No complementation was found between the North American subpopulations and the four early reported EU/I VCGs (22).

Aggressiveness of tested isolates was evaluated by inoculation of whole potato plants or in vitro-grown potato plantlets by root dipping $(1,21,27)$ or by inoculation of the soil or growth medium $(20,25,26)$. These assays are both expensive and time consuming. Therefore, in the current study, a recently reported bioassay (2), which enables the rapid assessment of a large number of isolates, was used.

Black dot is recognized as a major skin-blemishing disease of potato in Australia (9) but the degree of genetic diversity among isolates is unknown. The objectives of the current study were to (i) characterize VCGs among isolates of $C$. coccodes from Australia and assess their aggressiveness and (ii) determine genetic relations between VCG subpopulations from Europe/Israel, North America, and Australia.

\section{MATERIALS AND METHODS}

Collection of isolates. In all, 94 C. coccodes isolates were collected from 12 locations in Australia (Fig. 1), including 89 isolates from potato, 4 from the soil, and 1 from a weed (Solanum esuriale).

Forty-eight $C$. coccodes isolates from North America were randomly chosen from the collection in Pullman, WA. The isolates originated from 13 states in the United States and three provinces in Canada, and were isolated from potato (42 isolates), peppermint (3 isolates), tomato ( 2 isolates), and red pepper (1 isolate).

All $C$. coccodes isolates were placed on potato dextrose agar (PDA) and incubated in the dark at $25^{\circ} \mathrm{C}$ for 7 days. Conidia transferred to SA medium $(0.2 \%$ [wt/vol] sorbose, $1.5 \%$ [wt/vol] agar, and streptomycin sulfate at $100 \mathrm{ppm}$ ) were incubated for $24 \mathrm{~h}$ at $25^{\circ} \mathrm{C}$ in the dark. Monoconidial cultures were obtained

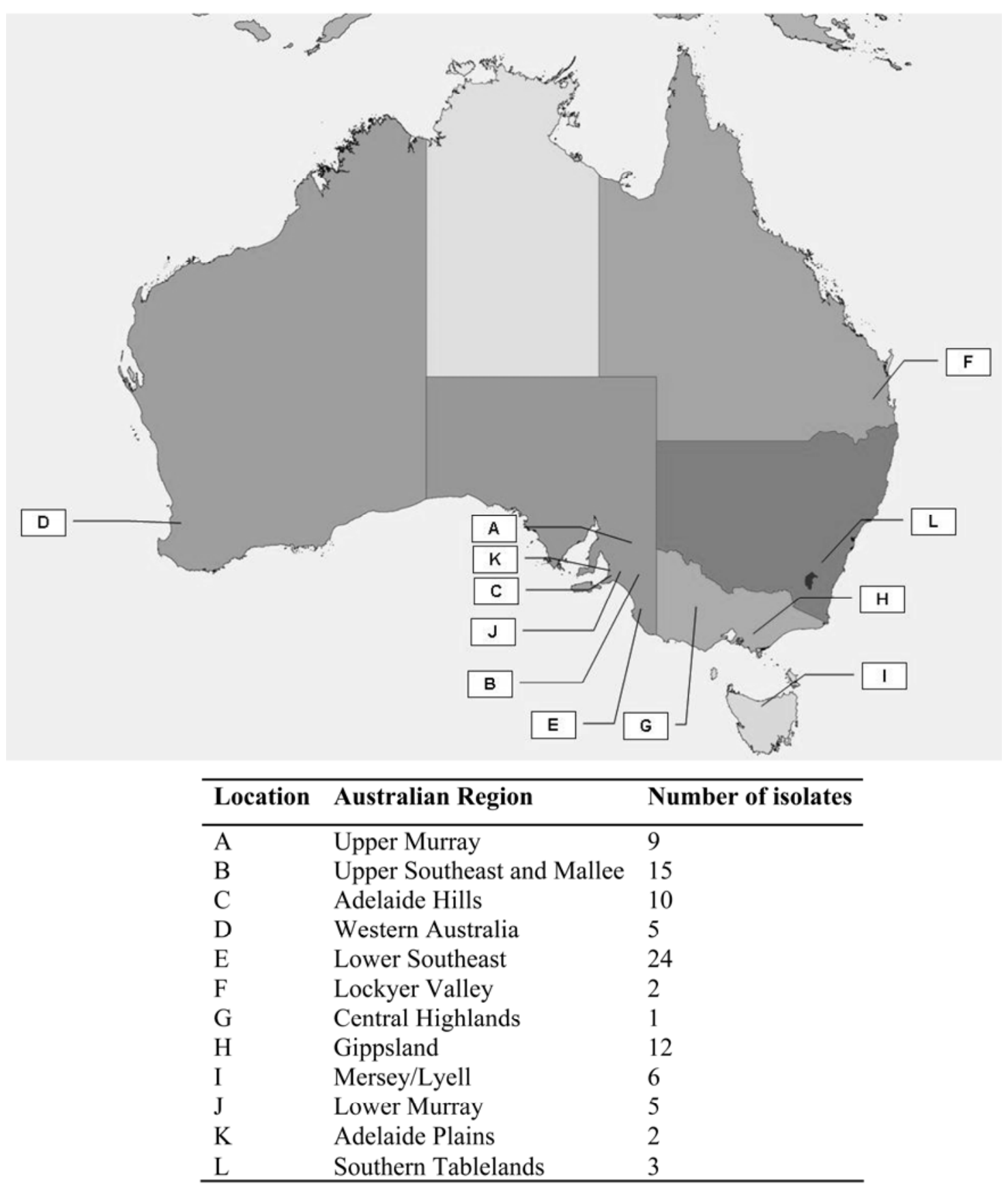

Fig. 1. Map of Australia indicating locations from which Colletotrichum coccodes isolates were collected. 
from each isolate (by micromanipulation) and maintained on Czapek dox agar (CDA) (Difco, Le Port de Claix, France) at $6^{\circ} \mathrm{C}$ $(21,25)$.

Selection and characterization of nitrate nonutilizing mutants. Nitrate nonutilizing (nit) mutants were generated using techniques described previously $(15,23)$. Water agar chlorate (WAC) medium (2\% agar, 3\% [wt/vol] potassium chlorate, and $0.02 \%$ [wt/vol] glucose) was used to select nit mutants. Ten $1-\mathrm{mm}$ mycelial plugs from monoconidial cultures of each isolate were placed on WAC medium and incubated at $25^{\circ} \mathrm{C}$ in the dark. After 21 days of incubation, the growing edges of the samples were transferred to petri plates containing CDA medium and incubated for 5 days at $25^{\circ} \mathrm{C}$. Colonies with a thin mycelium on CDA were considered nit mutants. Partial phenotyping of nit mutants (nit1/nit3 versus Nit $\mathrm{M}$ ) was carried out by placing two mycelial plugs of each isolate on both CDA and CDA amended with $0.02 \%$ (wt/vol) hypoxanthine. Plates were incubated for 5 days at $25^{\circ} \mathrm{C}$ in the dark. Colonies that developed on CDA supplemented with hypoxanthine with a wild-type phenotype and on CDA with a thin mycelium were classified as nit $1 /$ nit 3 mutants. Colonies with a thin mycelium on both media were classified as Nit M mutants.

Nit $M$ tester mutants of the previously assigned EU/I VCGs (24) were used to determine vegetative compatibility between EU/I VCGs and the Australian (AUS) and NA VCGs. Because Nit M tester mutants of the previously assigned NA VCGs (21) were not available, new mutants from isolates representing each of the seven VCGs were generated again for this study.

Complementation tests. Complementation between nit mutants was tested on CDA medium containing sodium nitrate as the only nitrogen source. One mycelial plug $(1 \mathrm{~mm})$ of Nit $\mathrm{M}$ and two mycelial plugs of nit $1 /$ nit 3 mutants were placed $1 \mathrm{~cm}$ apart in a triangular pattern. Plates were incubated for 14 days at $25^{\circ} \mathrm{C}$ in the dark. Complementation was usually evident after 7 to 14 days, characterized by prototrophic growth at the contact zone between the two complementary nit mutants. Mutants that positively complemented with one another were assigned to the same VCG.

Preparation of inoculum. Single-spore isolates were cultured on PDA in $9-\mathrm{cm}$ petri plates and incubated at $25^{\circ} \mathrm{C}$. Four days later, conidia were collected by water rinse from the agar surface and filtered through four layers of cheesecloth to remove mycelia. Conidial concentration, determined using a hemacytometer, was adjusted to $1 \times 10^{5}$ conidia $/ \mathrm{ml}$.

TABLE 1. Number and frequency of nitrate auxotrophic nitrate-nonutilizing (nit) mutants within vegetative compatibility groups (VCGs) of Australian (AUS) and North American (NA) Colletotrichum coccodes isolates

\begin{tabular}{|c|c|c|c|}
\hline \multirow[b]{2}{*}{ VCG } & \multirow[b]{2}{*}{ No. of replications ${ }^{x}$} & \multicolumn{2}{|c|}{ Frequency of nit mutants ${ }^{\mathrm{y}}$} \\
\hline & & nit $1 /$ nit 3 & Nit M \\
\hline AUS-1 & 230 & 93 & 13 \\
\hline AUS-2 & 130 & 44 & 5 \\
\hline AUS-3 & 220 & 74 & 24 \\
\hline AUS-4 & 120 & 35 & 8 \\
\hline AUS-5 & 70 & 26 & 1 \\
\hline AUS-6 & 20 & 8 & 3 \\
\hline AUS-non ${ }^{2}$ & 150 & 44 & 5 \\
\hline Total & 940 & $324(84.6 \%)$ & $59(15.4 \%)$ \\
\hline NA-1 & 90 & 29 & 8 \\
\hline NA-2 & 220 & 64 & 19 \\
\hline NA-3 & 50 & 15 & 3 \\
\hline NA-4 & 20 & 6 & 0 \\
\hline NA-5 & 50 & 19 & 5 \\
\hline NA-6 & 20 & 4 & 1 \\
\hline NA-7 & 30 & 10 & 1 \\
\hline Total & 480 & $147(79.9 \%)$ & $37(20.1 \%)$ \\
\hline
\end{tabular}

${ }^{\mathrm{x}}$ Total number of replications per VCG per isolate on water agar chlorate.

${ }^{y}$ Frequency of nit $1 / n i t 3$ and Nit M mutants generated for each VCG from 10 replications per isolate.

${ }^{z}$ Nonassigned.
Mature green tomato fruit inoculation. Mature green tomato fruit, weighing $\approx 150$ to $200 \mathrm{~g}$ each, of the $C$. coccodes-susceptible variety cv. 1402 (Zeraim Gedera, Israel) were picked from a commercial greenhouse. Fruit were surface-sterilized with $0.3 \%$ sodium hypochlorite for $10 \mathrm{~min}$, washed thoroughly with sterile water, and placed in a laminar hood until their surface was dry. A conidial suspension $(10 \mu \mathrm{l})$ was injected into the stem scar $(\approx 1 \mathrm{~cm}$ deep) using a 10- $\mu$ l glass syringe (Hamilton). Fruit injected with sterile distilled water served as controls. For each isolate, five fruit (each serving as a replicate) were inoculated. Injected fruit were placed in paper bags and incubated in the dark at $25^{\circ} \mathrm{C}$. Fruit were sliced open vertically in a laminar hood at 7 days postinoculation. The size (length and width) of the lesion adjacent to the stem scar (inside the fruit) was measured (2).

Statistical analysis. Data were analyzed statistically by SAS Software 6.12 (SAS Institute Inc., Cary, NC). The general linear model procedure was used to test the effects of inoculation on lesion size at the 0.05 level of probability. Analysis of variance was followed by mean separation using Student's multiple range test. All experiments were repeated twice and, because there were no differences between the two sets $(F=0.97, P>0.3251)$, data of each two experiments were pulled and then subjected to the statistical analysis.

\section{RESULTS}

Selection and characterization of Australian nit mutants. Recovery of spontaneous nit mutants from WAC medium onto CDA was optimal after 21 days of incubation at $25^{\circ} \mathrm{C}$ in the dark. On CDA, nit mutants are characterized by thin mycelia with a

TABLE 2. Classification of Colletotrichum coccodes isolates from different locations (Loc) in Australia to vegetative compatibility groups (VCGs)

\begin{tabular}{lrrrrrrrr}
\hline \multicolumn{7}{c}{ Loc } & \multicolumn{7}{c}{ Australian VCG } & \\
\cline { 2 - 7 } & 1 & 2 & 3 & 4 & 5 & 6 & Non $^{2}$ & Total \\
\hline A & 3 & 1 & 2 & 2 & 0 & 0 & 1 & 9 \\
B & 3 & 5 & 4 & 1 & 0 & 1 & 1 & 15 \\
C & 4 & 1 & 2 & 2 & 1 & 0 & 0 & 10 \\
D & 1 & 0 & 2 & 0 & 0 & 0 & 2 & 5 \\
E & 3 & 4 & 5 & 0 & 6 & 0 & 6 & 24 \\
F & 2 & 0 & 0 & 0 & 0 & 0 & 0 & 2 \\
G & 1 & 0 & 0 & 0 & 0 & 0 & 0 & 1 \\
H & 1 & 2 & 3 & 1 & 0 & 1 & 4 & 12 \\
I & 0 & 0 & 2 & 4 & 0 & 0 & 0 & 6 \\
J & 2 & 0 & 0 & 2 & 0 & 0 & 1 & 5 \\
K & 1 & 0 & 1 & 0 & 0 & 0 & 0 & 2 \\
L & 2 & 0 & 1 & 0 & 0 & 0 & 0 & 3 \\
Total & 23 & 13 & 22 & 12 & 7 & 2 & 15 & 94 \\
\hline
\end{tabular}

${ }^{\mathrm{z}}$ Nonassigned.

TABLE 3. Aggressiveness of Colletotrichum coccodes isolates originating from different Australian vegetative compatibility groups (VCGs) to mature green tomato fruit

\begin{tabular}{lcc}
\hline Australian VCG & Lesion size $(\mathrm{mm})^{\mathrm{y}}$ & No. tested/total $^{\mathrm{z}}$ \\
\hline 1 & $20.6 \mathrm{~b}$ & $13 / 23$ \\
2 & $21.4 \mathrm{ab}$ & $11 / 13$ \\
3 & $17.7 \mathrm{c}$ & $11 / 22$ \\
4 & $22.7 \mathrm{a}$ & $9 / 12$ \\
5 & $20.5 \mathrm{~b}$ & $5 / 7$ \\
6 & $19.6 \mathrm{bc}$ & $2 / 2$ \\
\hline y Aggressiveness of $C$. coccodes isolates to mature & green tomato fruit \\
inoculated by stem-scar injection 7 days postinoculation. Aggressiveness \\
was determined by lesion size (mm). Data were subjected to analysis of \\
variance and separated by Student's multiple range test. Different letters \\
within columns represent significant statistical differences among isolates at \\
$P<0.05$.
\end{tabular}

Vol. 100, No. 3, 2010 273 
greenish pigmentation. The mean frequency of all nit mutant sectors was $40.7 \%$ (383 mutants out of 940 sectors). Among the mutants, the nit $1 /$ nit 3 class made up $84.6 \%$ (324 nit $1 /$ nit 3 out of 383 recovered mutants), while Nit M mutants made up 15.4\% (59 Nit M out of 383 recovered mutants) (Table 1).

Selection of AUS-VCG testers and assignment into VCGs. During the first stages of the study, complementation tests were carried out using Nit M mutants generated from the different Australian isolates. Nit M mutants that demonstrated the ability to anastomose with a large number of isolates were chosen as VCG tester mutants. The isolates that were selected as AUS-VCG testers were 55.20 and 77.20 for AUS-VCG-1, 26.5 and 115.1 for AUS-VCG-2, 6.6 and 114.3 for AUS-VCG-3, 2.5 and 14.2 for

TABLE 4. Aggressiveness of Colletotrichum coccodes isolates originating from different Australian locations to mature green tomato fruit

\begin{tabular}{lcc}
\hline Location & Lesion size $(\mathrm{mm})^{\mathrm{y}}$ & No. tested/total $^{\mathrm{z}}$ \\
\hline $\mathrm{A}$ & $23.3 \mathrm{a}$ & $6 / 9$ \\
$\mathrm{~B}$ & $20.2 \mathrm{~b}$ & $11 / 15$ \\
$\mathrm{C}$ & $21.6 \mathrm{ab}$ & $6 / 10$ \\
$\mathrm{E}$ & $18.5 \mathrm{c}$ & $11 / 24$ \\
$\mathrm{H}$ & $17.6 \mathrm{c}$ & $4 / 12$ \\
$\mathrm{~J}$ & $21.2 \mathrm{ab}$ & $4 / 5$ \\
\hline
\end{tabular}

y Aggressiveness of $C$. coccodes isolates to mature green tomato fruit inoculated by stem-scar injection 7 days postinoculation. Aggressiveness was determined by lesion size (mm). Data were subjected to analysis of variance and separated by Student's multiple range test. Different letters within columns represent significant statistical differences among isolates at $P<0.05$. Locations for which four isolates or less were tested for aggressiveness were not included in the statistical analysis.

${ }^{\mathrm{z}}$ Number of isolates tested/total number of isolates.
AUS-VCG-4, 79/07K for AUS-VCG-5, and 12/07P and 97/07AH for AUS-VCG-6. Subsequently, all isolates were tested against these testers to examine VCGs.

Based on positive complementation reactions with the selected testers, six AUS-VCGs were identified: AUS-VCG-1 and AUSVCG-3 included 24.5 and $23.4 \%$ of all isolates, respectively; AUS-VCG-2 and AUS-VCG-4 included 13.8 and $12.8 \%$ of all isolates, respectively; and AUS-VCG-5 and AUS-VCG-6 included 7.5 and $2.1 \%$ of all isolates, respectively. Fifteen $(15.9 \%)$ of the isolates could not be assigned to any of the AUS-VCGs (Table 2). Isolates assigned to AUS-VCG-1 and AUS-VCG-3 were prevalent in most Australian locations, whereas isolates belonging to AUSVCG-2 and AUS-VCG-4 originated from approximately half (five or six) of the locations. Isolates originating from locations A, B, $\mathrm{C}, \mathrm{E}$, and $\mathrm{H}$ were assigned to four or five VCGs. Locations with the highest diversity of VCGs were also the most intensively cropped regions (data not shown).

No correlation was found between VCG and geographical origin. Although six of the seven (86\%) isolates assigned to AUSVCG-5 originated from location E (lower southeast Australia), this subpopulation comprised only $25 \%$ of the isolates originating from location E. Therefore, we could not draw any conclusions about specific geographical distribution.

Aggressiveness of $C$. coccodes isolates originating from Australia. Conidial suspensions from 51 Australian $C$. coccodes isolates representing all six AUS-VCGs were injected into the stem scar of mature green tomato fruit. All isolates tested caused necrotic lesions in the fruit. Infection was not detected in the water-inoculated controls. Significant differences in lesion size were observed among isolates assigned to different AUS-VCGs. Isolates belonging to AUS-VCG-4 produced the largest necrotic

TABLE 5. Complementation between Australian nitrate-nonutilizing nit1/nit3 mutants and North American (NA) Nit M mutants ${ }^{\mathrm{z}}$

\begin{tabular}{|c|c|c|c|c|c|c|c|c|c|c|c|}
\hline \multirow[b]{2}{*}{ VCG } & \multirow[b]{2}{*}{ Isolate } & \multicolumn{10}{|c|}{ Nit M mutants } \\
\hline & & $\begin{array}{c}\text { NA-1 } \\
1\end{array}$ & $\begin{array}{c}\text { NA-1 } \\
6\end{array}$ & $\begin{array}{c}\text { NA-2 } \\
10\end{array}$ & $\begin{array}{c}\text { NA-2 } \\
26\end{array}$ & $\begin{array}{c}\text { NA-2 } \\
47\end{array}$ & $\begin{array}{c}\text { NA-3 } \\
27\end{array}$ & $\begin{array}{l}\text { NA-4 } \\
\text { N-32 }\end{array}$ & $\begin{array}{c}\text { NA-5 } \\
36\end{array}$ & $\begin{array}{c}\text { NA-6 } \\
39\end{array}$ & $\begin{array}{c}\text { NA-7 } \\
45\end{array}$ \\
\hline \multirow[t]{4}{*}{ AUS-1 } & 6 & - & - & - & - & - & - & - & - & - & - \\
\hline & 58 & - & - & - & - & - & - & - & - & - & - \\
\hline & 81 & - & - & - & - & - & - & - & - & - & - \\
\hline & 114 & - & - & - & - & - & - & - & - & - & - \\
\hline & 62 & - & - & - & - & - & - & - & - & - & - \\
\hline & 115 & - & - & - & - & - & - & - & - & - & - \\
\hline & 118 & - & - & - & - & - & - & - & - & - & - \\
\hline \multirow[t]{3}{*}{ AUS-3 } & 7 & - & - & - & - & - & - & - & - & - & - \\
\hline & 13 & - & - & - & - & - & - & - & - & - & - \\
\hline & 15 & - & - & - & - & - & - & - & - & - & - \\
\hline \multirow[t]{4}{*}{ AUS-4 } & 2 & - & - & - & - & - & - & - & $*$ & - & - \\
\hline & 4 & - & - & - & - & - & - & - & $* *$ & - & - \\
\hline & 14 & - & - & - & - & - & - & - & $* *$ & - & - \\
\hline & 23 & - & - & - & - & - & - & - & $* *$ & - & - \\
\hline \multirow[t]{7}{*}{ AUS-5 } & $67 / 07 \mathrm{AH}$ & - & - & - & - & - & - & - & - & - & - \\
\hline & 78/07K & - & - & - & - & - & - & - & - & - & - \\
\hline & 79/07K & - & - & - & - & - & - & - & - & - & - \\
\hline & $112 / 07 \mathrm{~K}$ & - & - & - & - & - & - & - & - & - & - \\
\hline & $113 / 07 \mathrm{~K}$ & - & - & - & - & - & - & - & - & - & - \\
\hline & $131 / 07 \mathrm{~K}$ & - & - & - & - & - & - & - & - & - & - \\
\hline & $136 / 07 \mathrm{~K}$ & - & - & - & - & - & - & - & - & - & - \\
\hline \multirow[t]{2}{*}{ AUS-6 } & $12 / 07 \mathrm{P}$ & - & - & - & - & - & - & - & - & - & - \\
\hline & 97/07AH & - & - & - & - & - & - & - & - & - & - \\
\hline
\end{tabular}

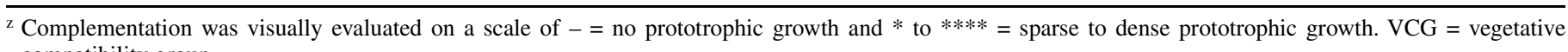
compatibility group. 
lesion size $(P<0.05)$ while those from AUS-VCG-3 produced the smallest necrotic lesions $(P<0.05)$ (Table 3$)$.

Significant differences in aggressiveness were also evident among isolates originating from different geographical locations in Australia (locations for which only four isolates or less were tested for aggressiveness were not included in the statistical analysis). Isolates originating from location $\mathrm{A}(P<0.05)$ produced the largest necrotic lesion size while isolates from locations $\mathrm{E}$ and $\mathrm{H}$ produced the smallest necrotic lesion size $(P<0.05)$ (Table 4).

Assignment of the North American isolates into VCGs. Mutants were selected for the North American isolates, and the mean frequency of recovery of nit mutants was $38.3 \%$ (184 mutants out of 480 sectors). Frequency of the nit $1 / n i t 3$ class was $79.9 \%$ (147 nit $1 /$ nit 3 out of 184 recovered mutants), and frequency of the Nit M class was $20.1 \%$ (37 Nit M mutants out of 184 recovered) (Table 1).

Based on positive complementation reactions with the chosen testers, we identified seven VCGs, as did Nitzan et al. (22). Each of the tested isolates was assigned exactly to the same previously established NA-VCGs: NA-VCG-2 included $45.8 \%$ of all isolates, NA-VCG-1 included 18.8\%, NA-VCG-3 and NA-VCG-5 included $10.4 \%$ each, NA-VCG-7 included $6.3 \%$, and NA-VCG-4 and NAVCG-6 included $4.2 \%$ of all isolates tested (data not shown).

TABLE 6. Summary of complementations among Europe/Israel (EU/I), North American (NA), and Australian (AUS) mutants

$\begin{array}{ccc}\text { AUS-VCG-4 } & \text { NA-VCG-5 } & \text { EU/I-VCG-7 } \\ \text { AUS-VCG-2 } & \ldots & \text { EU/I-VCG-2 } \\ \ldots & \text { NA-VCG-2 } & \text { EU/I-VCG-6 }\end{array}$

Complementation between Australian and North American mutants. Ten Nit $M$ mutants representing all seven NA-VCGs were used as testers: 1.7 and 6.1 for NA-VCG-1; 10.10b, 26.20, and 47.6 for NA-VCG-2; 27.9 for NA-VCG-3; N-32.2 for NAVCG-4; 36.6 for NA-VCG-5; 39.6 for NA-VCG-6; and 45.13 for NA-VCG-7 (Table 5). The North American tester isolates were complemented with two nit $1 /$ nit 3 mutants for each Australian isolate tested. A positive complementation reaction was evident only among isolates belonging to AUS-VCG-4 and the NA-VCG5 tester (Tables 5 and 6). No complementation was evident with nonassigned isolate mutants (data not shown).

Complementation between Australian and Europe/Israel mutants. Eleven Nit $M$ mutants representing the eight EU/IVCGs were used as testers (25). The Europe/Israel testers were complemented with two nit $1 /$ nit 3 mutants for each Australian isolate tested. A positive complementation reaction was obtained among isolates of AUS-VCG-2 and the EU/I-VCG-2 tester, and between the four isolates assigned to AUS-VCG-4 and the EU/IVCG-7 tester (Tables 6 and 7). No complementation was evident with nonassigned isolate mutants (data not shown).

Complementation between North American and Europe/ Israel mutants. Eleven Nit $\mathrm{M}$ mutants representing the eight EU/I-VCGs were used as testers (25). In the complementation test, the Europe/Israel testers were complemented with two nit1/nit3 mutants for each North American isolate (Table 8). A positive complementation reaction was evident among 18 of the 22 isolates belonging to NA-VCG-2 and the EU/I-VCG-6 tester and between all five isolates assigned to NAVCG-5 and the EU/I-VCG-7 tester (Tables 6 and 8). No complementation was evident with nonassigned isolate mutants (data not shown).

TABLE 7. Complementation between Australian (AUS) nitrate-nonutilizing nit1/nit3 mutants and Europe/Israel (EU/I) Nit M mutants ${ }^{\mathrm{z}}$

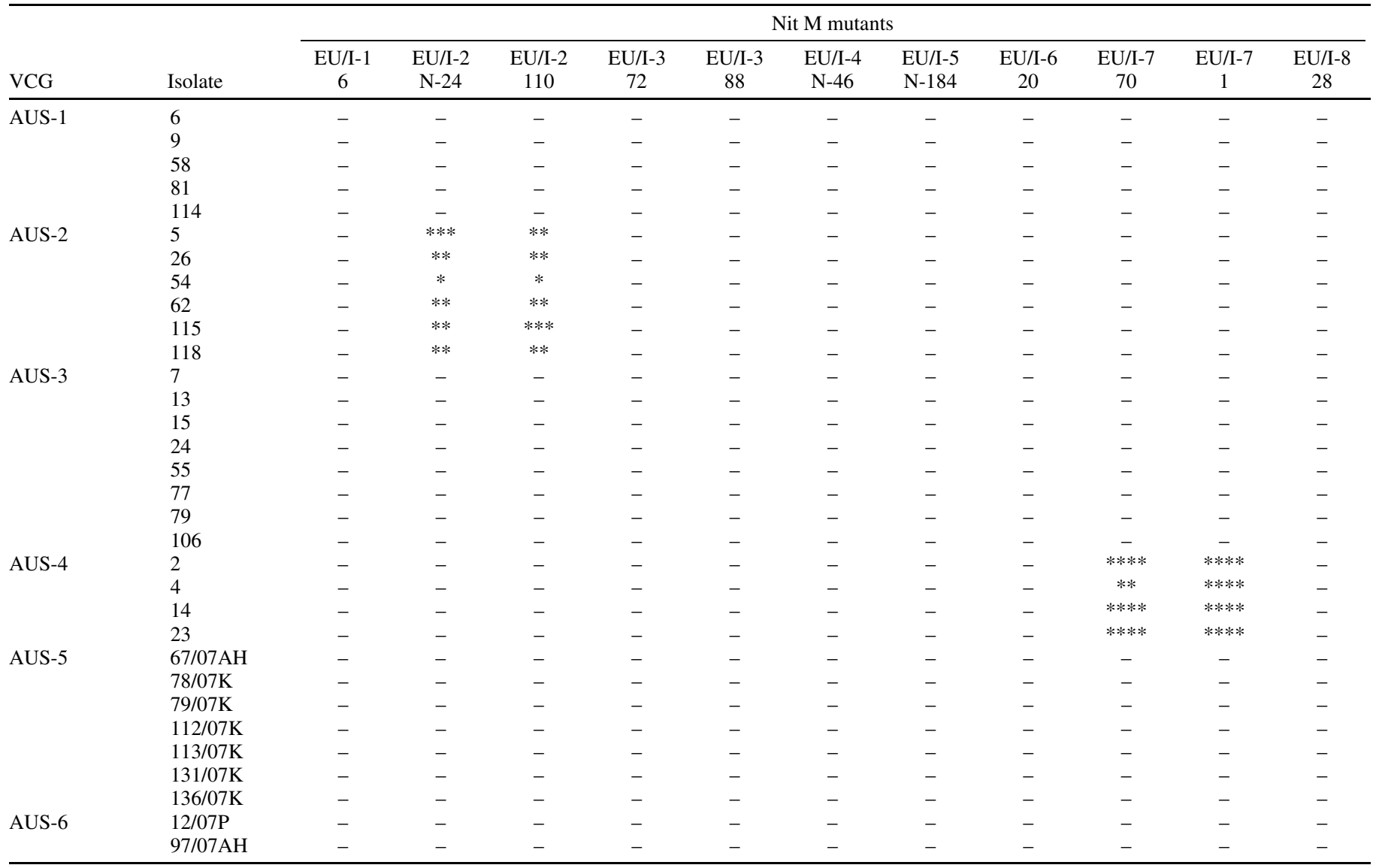

$\overline{{ }^{\mathrm{z}} \text { Complementation was visually evaluated on a scale of }-=\text { no prototrophic growth and } * \text { to } * * * *}=$ sparse to dense prototrophic growth. VCG $=$ vegetative compatibility group. 


\section{DISCUSSION}

This study demonstrates the occurrence of six C. coccodes VCGs in Australia; five of them are multimember and one comprises only two isolates.

Two EU/I-VCGs previously reported by Shcolnick et al. (25) had a specific geographical distribution: all 9 isolates assigned to EU/I-VCG-6 originated from The Netherlands and 34 of the 38 isolates assigned to EU/I-VCG-7 were from Scotland.

In the present study, although six of seven (86\%) isolates assigned to AUS-VCG-5 originated from location E, only six (25\%) of the isolates collected from location $\mathrm{E}$ were assigned to AUS-VCG-5 and, therefore, no correlation was found between geographical origin and AUS-VCG. This might result from higher transport of potato within the continent of Australia, compared with transport among different countries like Scotland and The Netherlands.
Isolates from AUS-VCG-4 were found to be the most aggressive while isolates from AUS-VCG-3 were the least aggressive. Differences in VCG aggressiveness may have practical implications in potato production. Soil and tuber assays for $C$. coccodes estimate pathogen levels but do not differentiate between VCGs $(4,6)$. If VCGs differ in aggressiveness, the presence of the pathogen in the soil or tubers does not necessarily indicate its damage potential. Data on VCG distribution within subpopulations, and on the relative aggressiveness of each VCG, enable a more accurate evaluation of potential damage and necessary control measures.

Significant differences in aggressiveness were also evident among isolates originating from different geographical locations in Australia. Isolates originating from location A were the most aggressive while those from locations $\mathrm{E}$ and $\mathrm{H}$ were the least aggressive (Table 4). Location $\mathrm{A}$ is at a lower latitude $\left(27\right.$ to $\left.34^{\circ} \mathrm{S}\right)$ than all other locations ( 37 to $41^{\circ} \mathrm{S}$ ), and the mean daily summer

TABLE 8. Complementation between Europe/Israel (EU/I) Nit M mutants and North American (NA) nitrate-nonutilizing nit1/nit3 mutants ${ }^{\mathrm{Z}}$

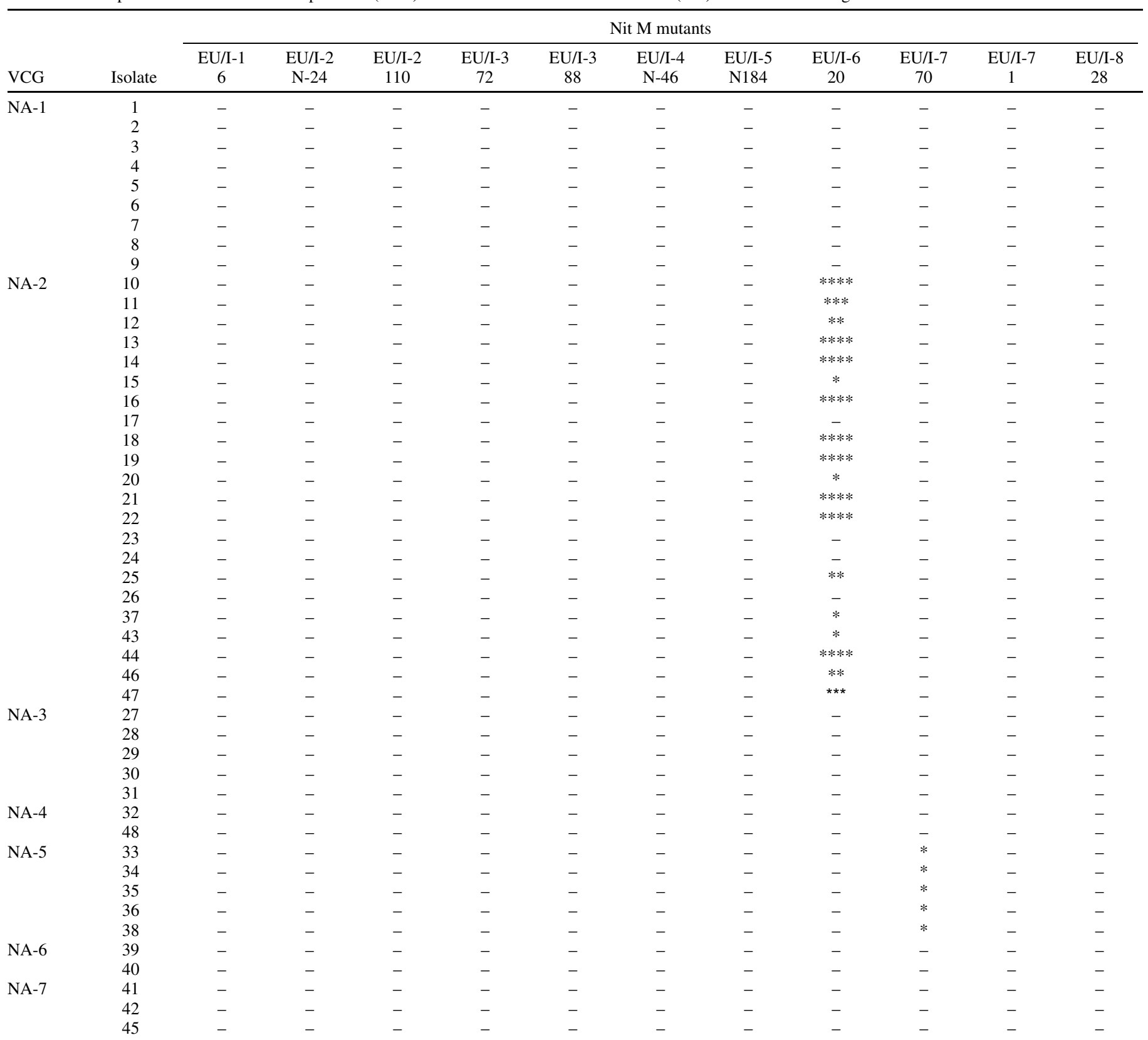

${ }^{\mathrm{z}}$ Complementation was visually evaluated on a scale of $-=$ no prototrophic growth and $*$ to $* * * *=$ sparse to dense prototrophic growth. VCG $=$ vegetative compatibility group. 
temperature in location $\mathrm{A}$ is higher $\left(29.7\right.$ to $\left.31.5^{\circ} \mathrm{C}\right)$ than in locations $\mathrm{E}$ and $\mathrm{H}\left(22.5\right.$ to $\left.24.9^{\circ} \mathrm{C}\right)$. Although black dot is most destructive in areas with dry and hot periods (16), this is the first report of aggressive isolates being prevalent in such areas.

With Verticillium dahliae, most VCGs and subgroups have been reported from diverse geographical origins, and an international tester set was established (11). Our results indicate that subpopulations of $C$. coccodes originating from the three tested continents are separate from one another, with different VCGs on each continent; however, a few clear interactions among VCGs indicate limited gene flow among continents. EU/I-VCG-7, AUSVCG-4, and NA-VCG-5 can complement with each other, indicating that these subpopulations are prevalent on all three continents. Two other complementation groups were found on each of two continents: AUS-VCG-2 complemented with EU/IVCG-2 and NA-VCG-2 complemented with EU/I-VCG-6 (Table 6 ). These results are in agreement with Nitzan et al. (22), who could not observe any anastomosis between NA-VCGs and the four first reported EU/I-VCGs (EU/I-VCG-1 to -4) (21). However, isolates from EU/I-VCG-6 and EU/I-VCG-7, which were identified later by Shcolnick et al. (25), anastomosed with VCGs from other continents characterized in the present study. The regional differences in the VCG composition of subpopulations observed within Europe (25), North America (22), and Australia suggest a possible environmental influence on the prevalence of these isolates to local conditions in specific areas. It seems unlikely that this differentiation is due to host isolation, because potato can be infected by isolates of all VCGs and by isolates which originate from potato or from other hosts (22). The linkage between subpopulations could be a result of the limited exchange of seed and ware potato tubers between continents but it could also be due to selection or a limited number of polymorphic vegetative incompatibility genes.

Interestingly, the isolates from VCGs that are dispersed globally are also highly aggressive. Our findings showed that AUS-VCG-2 and AUS-VCG-4, which anastomosed internationally, are composed of the second and first most aggressive isolates, respectively. Nitzan et al. (22) concluded that NA-VCG-2 and NAVCG-5 were the most aggressive subpopulations. These VCGs also complemented with subpopulations from different geographical origins. Isolates assigned to EU/I-VCG-7 caused the highest symptoms on shoots while isolates assigned to EU/I-VCG-6 (and EU/I-VCG-5) caused the highest colonization index. These EU/IVCGs are also the ones that could anastomose globally. EU/IVCG-2 is an exception to the hypothesis that the most aggressive VCGs complement internationally, because it was not found to be more aggressive than other EU/I-VCGs, by any scale. Therefore, further studies are needed to validate this hypothesis.

It should be mentioned that no correlation was found between the number of isolates within a VCG and the fact that it complemented with a VCG from a different geographical origin. Only NA-VCG-2 and EU/I-VCG-7 were the largest groups in their geographical origin (containing 36.5 and $27.8 \%$ of all isolates, respectively); the rest of the VCGs were not.

NA-VCG isolates characterized by amplified fragment length polymorphism (AFLP) were clustered into five corresponding groups (10). VCG and AFLP analysis cluster $C$. coccodes isolates into the same groups in the majority of the tested isolates, indicating that these methods, although not measuring the same parameters, are detecting the same basic level of genetic variation. Isolates from NA-VCG1 and NA-VCG3 were closely related, as were isolates from NA-VCG2 and NA-VCG5. Isolates from NAVCG4 were clustered with NA-VCG2 and NA-VCG5. NA-VCG6 isolates were the most diverged from other groups. VCG assignment is limited by the ability of all isolates to generate nit mutants and by an isolate's ability to anastomose; therefore, AFLP analysis would be an efficient tool for further studies analyzing the genetic diversity within and among the groups (10).

\section{ACKNOWLEDGMENTS}

We thank C. Weinstein for editing this manuscript.

\section{LITERATURE CITED}

1. Aqeel, A. M., Pasche, J. S., and Gudmestad, N. C. 2008. Variability in morphology and aggressiveness among North American vegetative compatibility groups of Colletotrichum coccodes. Phytopathology 98:901-909.

2. Ben Daniel, B., Bar Zvi, D., and Tsror (Lahkim), L. 2009. An improved large-scale screening method for assessment of Colletotrichum coccodes aggressiveness using mature green tomato. Plant Pathol. 58:497-503.

3. Brooker, N. L., Leslie, J. F., and Dickman, M. B. 1991. Nitrate nonutilizing mutants of Colletotrichum and their use in studies of vegetative compatibility and genetic relatedness. Phytopathology 81:672-677.

4. Carnegie, S. F., Choiseul, J. W., and Roberts, A. M. I. 2003. Detection of Colletotrichum coccodes and Helminthosporium solani in soils by bioassay. Plant Pathol. 52:13-51.

5. Correll, J. C., Gordon, T. R., and McCain, A. H. 1988. Vegetative compatibility and pathogenicity of Verticillium albo-atrum. Phytopathology 78:1017-1021.

6. Cullen, D. E., Lees, A. K., Toth, I. K., and Duncan, J. M. 2002. Detection of Colletotrichum coccodes from soil and potato tubers by conventional PCR and real-time quantitative PCR. Plant Pathol. 51:281-292.

7. Dillard, H. 1992. Colletotrichum coccodes: The pathogen and its hosts. Pages 225-236 in: Colletotrichum: Biology, Pathology and Control. J. Bailey and M. Jeger, eds. CAB International, Wallingford, UK.

8. Glais-Varlet, I., Bouchek-Mechiche, K., and Andrivon, D. 2004. Growth in vitro and infectivity of Colletotrichum coccodes on potato tubers at different temperatures. Plant Pathol. 53:398-404.

9. Harding, R., Wicks, T., and Hall, B. 2005. Black dot: The cause of tuber infections near harvest. Pages 121-123 in: Proc. 16th Triennial Conf. Eur. Assoc. Potato Res., Bilbao. E. Ritter and A. Carrascal, eds. Servicio Central Publications (Gobierno Vasco).

10. Heilmann, L. J., Nitzan, N., Johnson, D. A, Pasche, J. S., Dowtkott, C., and Gudmestad, N. 2006. Genetic variability in potato pathogen Colletotrichum coccodes as determined by amplified fragment length polymorphism and vegetative compatibility group analyses. Phytopathology 96:1097-1107.

11. Joaquim, T. R., and Rowe, R. 1991. Vegetative compatibility and virulence of strains of Verticillium dahliae from soil and potato plants. Phytopathology 81:552-558.

12. Katan, T., and Katan, J. 1988. Vegetative compatibility grouping of Fusarium oxysporum f. sp. vasinfectum from tissue and rhizosphere of cotton plants. Phytopathology 78:852-855.

13. Katan, T., and Shabi, E. 1996. Vegetative compatibility among isolates of Colletotrichum gloeosporioides from almond in Israel. Eur. J. Plant Pathol. 102:597-600.

14. Katan, T., Zamir, D., Sarfati, M., and Katan, J. 1991. Vegetative compatibility groups and subgroups in Fusarium oxysporum f. sp. radicislycopersici. Phytopathology 81:255-262.

15. Korolev, N., and Katan, T. 1997. Improved medium for selecting nitratenonutilizing (nit) mutants of Verticillium dahliae. Phytopathology 87:1067-1070.

16. Korolev, N., Katan, J., and Katan, T. 2000. Vegetative compatibility groups of Verticillium dahlia in Israel: Their distribution and association with pathogenicity. Phytopathology 90:529-536.

17. Lees, A. K., and Hilton, A. J. 2003. Black dot (Colletotrichum coccodes): An increasingly important disease of potato. Plant Pathol. 52:3-12.

18. Leslie, F. J. 1993. Fungal vegetative compatibility. Annu. Rev. Phytopathol. 31:127-150.

19. Marlatt, M. L., Correll, J. C., Kaufmann, P., and Cooper, P. E. 1996. Two genetically distinct populations of Fusarium oxysporum f. sp. lycopersici race 3 in the United States. Plant Dis.80:1336-1342.

20. Nitzan, N., Cummings, T. F., and Johnson, D. A. 2005. Effect of seedtuber generation, soilborne inoculum, and azoxystrobin application on development of potato black dot caused by Colletotrichum coccodes. Plant Dis. 89:1181-1185.

21. Nitzan, N., Hazanovsky, M., Tal, M., and Tsror (Lahkim), L. 2002. Vegetative compatibility groups in Colletotrichum coccodes, the causal agent of black dot in potato. Phytopathology 92:827-832.

22. Nitzan, N., Tsror (Lahkim), L., and Johnson, D. A. 2006. Vegetative compatibility groups and aggressiveness of North American isolates of Colletotrichum coccodes, the causal agent of potato black dot. Plant Dis. 90:1287-1292.

23. Puhalla, J. E. 1985. Classification of strains of Fusarium oxysporum on the basis of vegetative compatibility. Can. J. Bot. 63:179-183.

24. Puhalla, J. E., and Hummel, M. 1983. Vegetative compatibility groups 
within Verticillium dahliae. Phytopathology 73:1305-1308.

25. Shcolnick, S., Dinoor, A., and Tsror (Lahkim), L. 2007. Additional vegetative compatibility groups in Colletotrichum coccodes subpopulations from Europe and Israel. Plant Dis. 91:805-808.

26. Tsror (Lahkim), L. 2004. Effect of light duration on severity of black dot caused by Colletotrichum coccodes. Plant Pathol. 53:288-293.

27. Tsror (Lahkim), L., Hazanovsky, M., Mordechi-Lebiush, S., and Sivan, S.
2001. Aggressiveness of Verticillium dahliae isolates from different vegetative compatibility groups to potato and tomato. Plant Pathol. 50:477-482.

28. Tsror (Lahkim), L., and Johnson, D. A. 2000. Colletotrichum coccodes on potato. Pages 362-373 in: Colletotrichum-Host Specificity, Pathology and Host-Pathogen Interaction. D. Prusky, S. Freeman, and M. B. Dickman, eds. The American Phytopathological Society, St. Paul, MN. 